\title{
Springback/Springforward Behaviour of DP Steels Used in the Automotive Industry
}

\author{
Yeliz UMUR, Hakan AYDIN, Kurtulus YIGIT, Ali BAYRAM
}

\begin{abstract}
The springback/springforward behaviour in a V-die/punch of DP600 and DP780 steels used in the automotive industry was investigated. For this study, experiments were carried out by using different combinations of parameters, including material thickness, die/punch radius, bending angle and rolling direction and the resulting measurements showed that the DP780 steel consistently exhibited greater springback values than the DP600. Augmentation of the rolling direction at an angle from $0^{\circ}$ to $90^{\circ}$ and punch radius inhibited springback formation and hastened springforward, particularly for small bending angles. The springback angle decreased with increasing material thickness and curvature radius, and increased with the bending angle, particularly for the punch tip radius of $2 \mathrm{~mm}$. Increasing the ratio of curvature radius to material thickness $\left(t^{+}{ }^{1}\right)$ also caused the springback to decline. In addition, a new dimensionless parameter was developed and the critical value for calculating the transition from springback to springforward was determined.
\end{abstract}

Keywords: die/punch radius; DP steels; rolling direction; springback/springforward; V-bending

\section{INTRODUCTION}

The springback/springforward phenomenon plays a significant role in the metal forming processes used in the manufacture of such products as vehicle parts, household goods, electronics, medical devices, etc. Therefore, the prediction of springback is of vital importance in acquiring the desired shape of a product.

The effect of springback on sheet metals has been examined by several researchers, who mainly focused on such factors as the influence of material thickness, yield stress, lubrication and punch radius. Carden et al. [1] showed that springback was dramatically reduced as the tensile stress approached the yield stress and that very low friction conditions increased spring back. Moon et al. [2] found that the combination of hot die and cold punch reduced the amount of springback by up to $20 \%$ in U-bent aluminium 1050 sheets, when compared to conventional room-temperature bending. Tekaslan et al. [3] found that springback in a $\mathrm{V}$-shaped die decreased proportionally with the thickness and that the punch load duration on the material caused the springback value to decrease. Ragai et al. [4] showed that the blank holder force resulted in smaller springback angles and that when a lubricant was applied, there was greater spring back with the same blank holder force. Garcia-Romeu et al. [5] reported that a larger bending angle gave rise to greater springback. In addition, they found that springback reduced with the material thickness and, as expected, lower springback values were observed in aluminium alloys than in stainless steel. Tekaslan et al. [6] observed that springback decreased with the punch load duration and increased with material thickness and the bending angle.

Rahmani et al. [7] investigated the effect of material thickness on springback in the V-die bending of CK67 steel and found that increasing the sheet thickness resulted in a decrease in the springback and negative springback angle. Bakhshi-Jooybari et al. [8] studied the springback of CK67 steel in the V-die and U-die bending processes and found that no springforward occurred in the U-die bending; however, in some cases there was springforward in the Vdie bending. In both the U- and V-die processes, increases in material thickness resulted in a decrease in the springback/springforward angle. In the V-die bending, there was no springback with any specific punch tip radius size, while reduced springforward was recorded with a greater punch tip radius. In the U-die bending, while there was no spring forward, the springback increased with a greater die punch tip radius. In relation to the rolling direction, springback/springforward increased with increasing bending angles. In terms of the rolling direction, the $0^{\circ}$ orientation provided the optimal conditions for both $\mathrm{U}$ - and V-die bending.

Narayanasamy and Padmanabhan [9] showed that lubrication of both the punch and the die was more effective in reducing springback than lubrication of the punch or the die alone and that the lubricant technique was an important factor in developing a successful bending operation. The springback variation was also a function of lubrication in larger curvature bending. Parsa et al. [10] investigated the springback of double-curved aluminium/polypropylene/aluminium sandwich sheets and showed that augmentation of the tool radius decreased the springback in all rolling directions and that the variation of thickness of the sandwich panels influenced the amount of springback in both directions. Moreover, by increasing the thickness of the sandwich sheet, the amount of springback increased in all ranges of curvatures. Barouzeh and Mondali [11] investigated a $\mathrm{V}$-shape die with a $60^{\circ}$ angle at temperatures of 25,200 and $300^{\circ} \mathrm{C}$ using DP600 steel, and reported that the amount of spring back decreased with the rise in temperature, and that the lowest springback was obtained at $300^{\circ} \mathrm{C}$.

Chongthairungruang et al. [12] studied the springback effect for advanced high strength dual-phase steel and found that a higher pre-deformation state led to a noticeable increase in the springback effect, and that consideration of the variable elastic modulus improved the accuracy of the springback prediction. Dilipak et al. [13] investigated the effects of material properties and punch tip radius on springforward in $\mathrm{V}$-die $90^{\circ}$ bending processes and showed that the amount of springforward decreased with punch tip radius and the duration of the punch contact on the material. Davoodi and Zareh-Desari [14] observed that increased material thickness caused a considerable reduction in springback but that springback increased with elastic layer thickness. 
As mentioned above, springback is significantly influenced by the tensile/yield strengths, material thickness, temperature, lubrication, bending angle, die/punch radius and rolling direction. None of the previous studies has systematically considered the combined effects of all parameters on springback predictions, and studies on the degree of springback of D600 and DP780 steels have not been widely reported in the literature. The present experimental research was conducted in order to fill some aspects of this gap by taking the major parameters into consideration.

\section{EXPERIMENTAL PROCEDURE}

All measurements were carried out in a V-type die and punch set mounted on a C-type hydraulic press with the capacity of $30 \mathrm{kN}$.
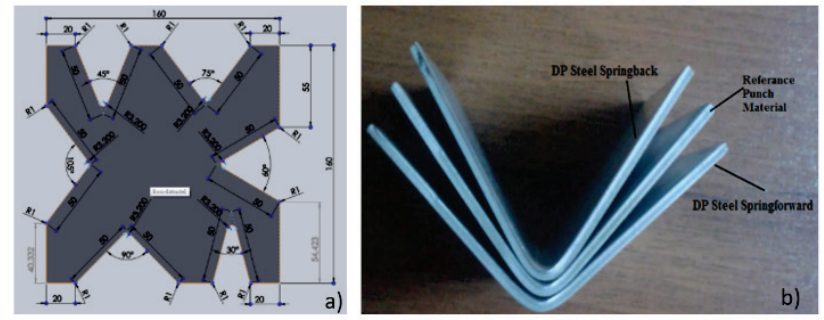

Figure 1 a) V-die bending configurations; b) Illustration of springback/springforward in the bending proces

The schematic configurations of $\mathrm{V}$-die bending, and an illustration of springback/springforward in the bending process are given in Fig. 1(a) and (b), respectively. The 3type $\mathrm{V}$-die included six different bending angles with three different die tip/punch radii which, along with the corresponding punches above the die, were fixed on the hydraulic press.
The DP600 and DP780 steel samples were precisely cut from rolled sheets in the rolling directions of $0^{\circ}$ (parallel), $45^{\circ}$ (diagonal) and $90^{\circ}$ (perpendicular) and were appropriately cleaned and placed on the die in the correct position for bending. After the samples were put on the die, the punch, with a constant stroke speed of $12.5 \mathrm{~mm} / \mathrm{s}$, was pushed down gradually and as soon as the sample touched the die tip, the punch movement was stopped and it was automatically withdrawn.

The bending stroke distance and the punch movement were recorded with a digital indicator mounted on the press. In order to determine more clearly the influence of the bending angle on the springback process, for each die radius, six different bending angles of $30^{\circ}, 45^{\circ}, 60^{\circ}, 75^{\circ}$, $90^{\circ}$ and $105^{\circ}$ were used for the measurements and the adjustment of the experimental setup to the loading/unloading conditions was carefully implemented. The chemical composition and the mechanical properties of these steels are given in Tab. 1 and Tab. 2 respectively. The surface roughness in all specimens varied from 1.2 to $1.44 \mu \mathrm{m}$. The samples were prepared to dimensions of 60 $\mathrm{mm}$ in width, $90 \mathrm{~mm}$ in length and $1.2,1.6$ and $2.0 \mathrm{~mm}$ in thickness, and the punch tip and corresponding die radii were chosen as 2, 3 and $4 \mathrm{~mm}$. The amount of springback was directly measured by means of a manual angle gauge (protractor) with \pm 1 minute sensitivity.

\section{$3 \quad$ RESULTS AND DISCUSSION}

This section provides the experimental results for the springback/springforward behaviors of DP600 and DP780 steels with punch radii of 2,3 and $4 \mathrm{~mm}$. The measurements with the $2 \mathrm{~mm}, 3 \mathrm{~mm}$ and $4 \mathrm{~mm}$ punch radii will be presented in turn at the rolling directions of $0^{\circ}$ (parallel), $45^{\circ}$ (diagonal) and $90^{\circ}$ (perpendicular).

Table 1 The chemical composition of the experimental sheet steel used in this investigation

\begin{tabular}{|c|c|c|c|c|c|c|c|c|c|c|c|}
\hline Sheet Steel & $\mathrm{C}$ & $\mathrm{Si}$ & $\mathrm{Mn}$ & $\mathrm{P}$ & $\mathrm{S}$ & $\mathrm{Al}$ & $\mathrm{Nb}$ & $\mathrm{Mg}$ & $\mathrm{Cr}$ & $\mathrm{Ti}$ & $\mathrm{V}$ \\
\hline DP600 & 0.095 & 0.337 & 1.933 & 0.023 & 0.001 & 0.024 & 0,005 & 0.0004 & 0.229 & 0.002 & 0.005 \\
\hline DP780 & 0.152 & 0.283 & 2.068 & 0.025 & 0.003 & 0.027 & 0.005 & 0.0005 & 0.26 & 0.003 & 0.005 \\
\hline
\end{tabular}

Table 2 The mechanical properties of the experimental sheet steels used in this investigation

\begin{tabular}{|c|c|c|c|c|c|}
\hline \multirow{2}{*}{ Sheet Steel } & $\begin{array}{c}\text { Elasticity modulus } \\
E / \mathrm{GPa}\end{array}$ & $\begin{array}{c}\text { Yield stress } \\
R_{p 0,02} / \mathrm{MPa}\end{array}$ & $\begin{array}{c}\text { Ultimate tensile stress } \\
R_{m} / \mathrm{MPa}\end{array}$ & $\begin{array}{c}\text { Total elongation } \\
A / \%\end{array}$ & $\begin{array}{c}\text { Hardness / } \\
\mathrm{HV}_{1}\end{array}$ \\
\hline DP600 & 210.1 & 357.5 & 598.4 & 9.72 & 198 \\
\hline DP780 & 210.7 & 528.3 & 748.1 & 7.80 & 234 \\
\hline
\end{tabular}

\subsection{Measurements with $2 \mathrm{~mm}$ Punch Radius}

Fig. 2 shows the influence of sheet thickness on springback at the rolling direction of $0^{\circ}$ for a die/punch tip radius of $2 \mathrm{~mm}$ in the bending of $30^{\circ}, 45^{\circ}, 60^{\circ}, 75^{\circ}, 90^{\circ}$ and $105^{\circ}$ angles, respectively. As can be seen in this figure, the amount of springback in both materials was decreased by increasing the sheet thickness for the $30^{\circ}$ bending angle, which is in good agreement with the results of Garcia and Romeu [5], Tekaslan et al. [6] and Bakhshi-Jooybari et al. [8]. The springback value at $45^{\circ}$ in the DP780 sample was almost 15\% higher than in the DP600 for the $1.2 \mathrm{~mm}$ thickness and diminished slightly with the material thickness. The springback for the $60^{\circ}$ bending angle increased with the thickness in the DP600 sample. The springback for the $90^{\circ}$ bend in both materials, initially decreased, and then increased, similar to that of the DP780 for the $60^{\circ}, 75^{\circ}$ and $105^{\circ}$ bending angles. The springback values in the higher-carbon concentrated DP780 dualphase steel owing to the higher martensite phase, as shown in Fig. 3, were greater than in the DP600 for all measurements at the rolling direction of $0^{\circ}$. These results are partly in accord with those of Barouzeh and Mondali [11].

Fig. 4 indicates the effect of material thickness on springback in the rolling direction of $45^{\circ}$ with a punch tip radius of $2 \mathrm{~mm}$ for the bending angles of $30^{\circ}, 45^{\circ}, 60^{\circ}, 75^{\circ}$, $90^{\circ}$ and $105^{\circ}$. As can be seen in this figure, the amount of springback in both materials declined with increasing specimen thickness for the $30^{\circ}$ and $75^{\circ}$ bending angles and reached zero at a material thickness of nearly $1.8 \mathrm{~mm}$ (by extrapolation), at which point springforward was initiated and reached $0.5^{\circ}$. This indicates the presence of a turning point, in other words, a transition point, from springback to 
springforward that can be simply defined in a dimensionless form as $A=\left(r t^{-1}\right) \cdot\left(2 \pi \theta \cdot 360^{-1}\right)^{-1}$, where $\mathrm{r}$ is the punch radius, $\mathrm{t}$ the material thickness and the $\theta$ bending angle.
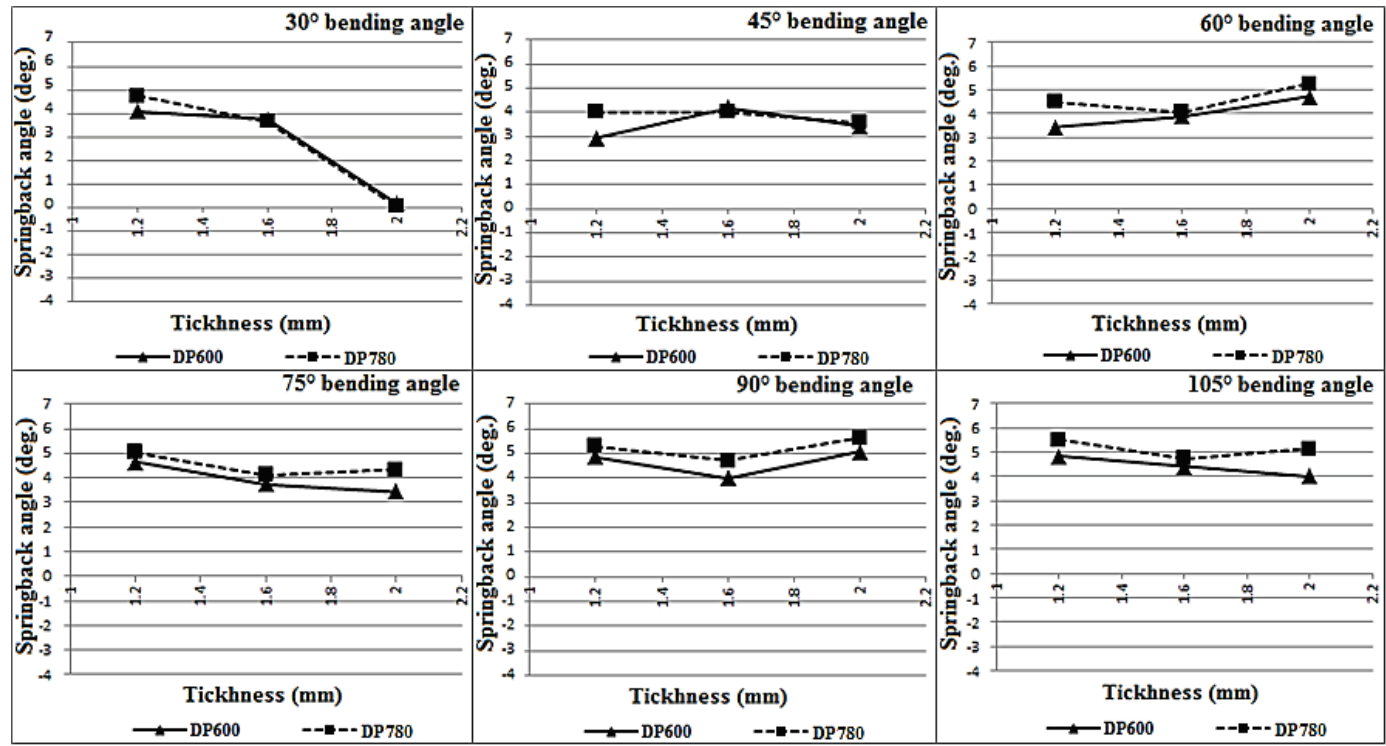

Figure 2 Variation of springback with material thickness at different bending angles for a punch tip radius of $2 \mathrm{~mm}$ (rolling direction: $0^{\circ}$ )

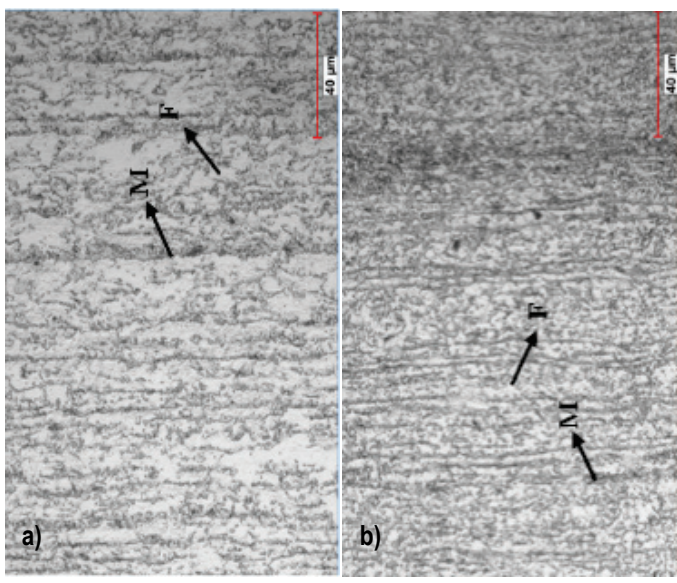

Figure 3 Microstructures of DP600 (a) and DP780 (b) sheet steels.M: Martensite; F: Ferrite
With this equation, the critical value from the springback to springforward was determined as 1.92 . The turning point was observed at $2 \mathrm{~mm}$ thickness in the $0^{\circ}$ rolling direction and at about $1.95 \mathrm{~mm}$ thickness in the $45^{\circ}$ rolling direction indicating that the enhancement in the rolling direction accelerated the transition. The amount of springback in both materials initially decreased and then increased for the $60^{\circ}$ and $90^{\circ}$ bending angles, but exhibited the highest value for the $45^{\circ}$ angle at $1.6 \mathrm{~mm}$ thickness. On the other hand, for the $105^{\circ}$ bending angle, the springback deviation fell steadily in the DP600, but rose slightly in the DP780. As can be seen in the zero degree rolling direction, all measured springback values were again greater in the DP780 dual-phase steel than in the DP600. Similar results were presented by Rahmani et al. [7] and Bakhshi-Jooybari et al. [8].

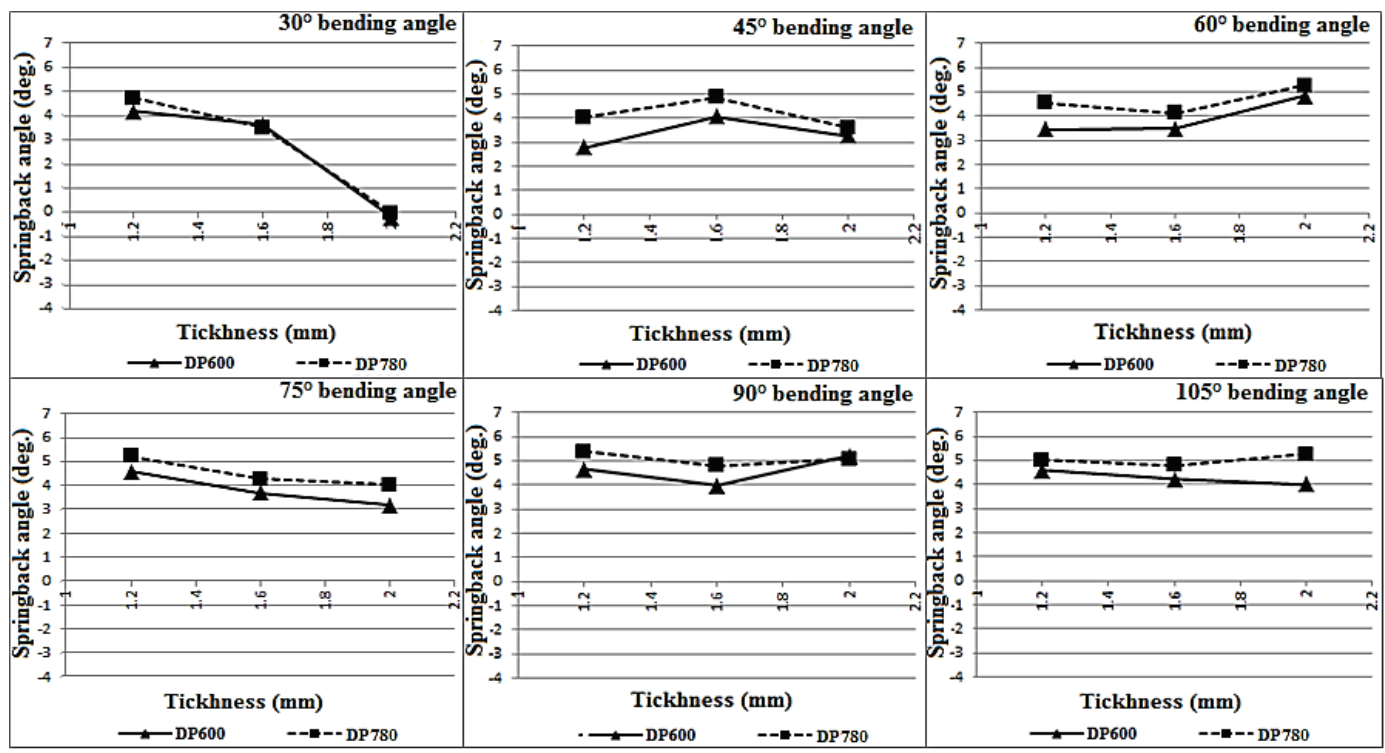

Figure 4 Variation of springback with material thickness at different bending angles for a punch tip radius of $2 \mathrm{~mm}$ (rolling direction: $45^{\circ}$ 


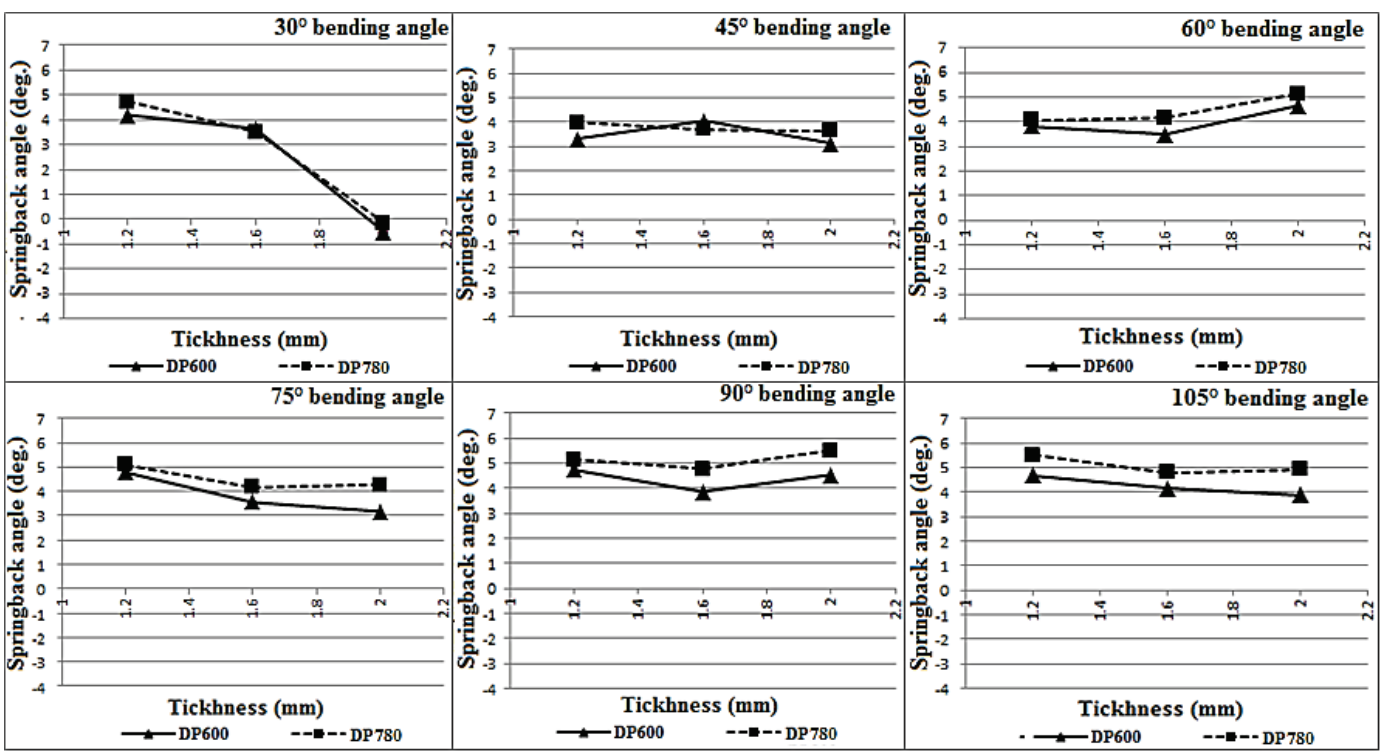

Figure 5 Variation of springback with material thickness at different bending angles for a punch tip radius of $2 \mathrm{~mm}$ (rolling direction: $90^{\circ}$ )

\subsection{Measurements with $3 \mathrm{~mm}$ Punch Radius}

Fig. 6 presents the distribution of springback values in relation to material thickness for a punch tip radius of $3 \mathrm{~mm}$ in the rolling direction of $0^{\circ}$ for the bending angles of $30^{\circ}$, $45^{\circ}, 60^{\circ}, 75^{\circ}, 90^{\circ}$ and $105^{\circ}$, respectively. Springforward occurred in all points and material thickness for the $30^{\circ}$ bending angle, and was reduced to as low as $2^{\circ}$ at a thickness of $1.2 \mathrm{~mm}$. These results are partly in agreement with the studies of Bakhshi-Jooybari et al. [8], Dilipak et al. [13] and Grizelj et al. [15]. The springback started as low as $4^{\circ}$, but then rose for the $60^{\circ}$ and $90^{\circ}$ bending angles. The opposite was true for the $45^{\circ}$ and $75^{\circ}$ bending angles, particularly in the DP780. The springback for the $105^{\circ}$ bending angle decreased with increased material thickness, as was expected. It should be also noted that the springback decreased with increasing the punch tip radius. This can be attributed to the higher outer surface stress of the sheet metal with the smaller punch tip radius.

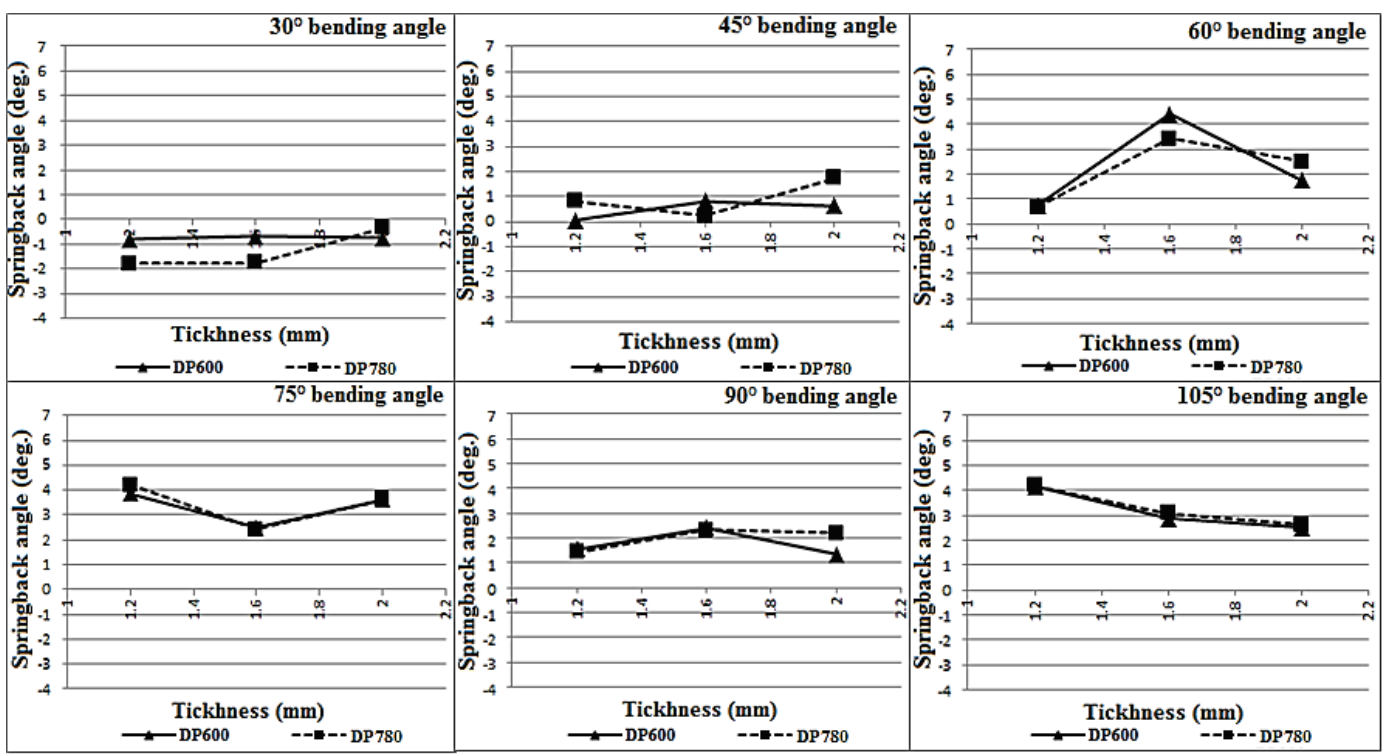

Figure 6 Variation of springback with material thickness at different bending angles for a punch tip radius of $3 \mathrm{~mm}$ (rolling direction: $0^{\circ}$ )

Fig. 7 indicates the springback values in relation to material thickness for a punch tip radius of $3 \mathrm{~mm}$ in the diagonal direction $\left(45^{\circ}\right)$ for the bending angles of $30^{\circ}, 45^{\circ}$, $60^{\circ}, 75^{\circ}, 90^{\circ}$ and $105^{\circ}$, respectively. Springforward took place again for the $30^{\circ}$ bending angle all the way through, and nearly occurred for the $45^{\circ}$ bending angle, especially at a thickness of $1.2 \mathrm{~mm}$. These results are in agreement with the research of Grizelj et al. [15]. The springback first increased up to midpoint and then decreased to the last position for the $60^{\circ}$ and $90^{\circ}$ bending angles. This trend was more pronounced for the $60^{\circ}$ angle. The springback first decreased and then slightly increased for $75^{\circ}$, and decreased with increased material thickness at the $105^{\circ}$ bending angle.

Fig. 8 shows the springback angles with material thickness for a punch tip radius of $3 \mathrm{~mm}$ in the perpendicular direction and for the bending angles of $30^{\circ}$, $45^{\circ}, 60^{\circ}, 75^{\circ}, 90^{\circ}$ and $105^{\circ}$, respectively. The springforward became more remarkable for $30^{\circ}$ and almost exceeded $2^{\circ}$ at a $1.2 \mathrm{~mm}$ thickness, particularly in DP780. There was initially no sign of springback/springforward at the $45^{\circ}$ bending angle and $1.2 \mathrm{~mm}$ thickness, and then, 
springback increased with the thickness. The springback first increased up to midpoint and then decreased to the final position for the $60^{\circ}$ and $90^{\circ}$ bending angles, as in the transverse case, which shows a similarity to the investigations of Barouzeh and Mondali [11] and Tekiner
[16]. Similar to the previous case, the springback angle first decreased and then slightly increased at $75^{\circ}$, and finally, decreased steadily all the way with the material thickness for the $105^{\circ}$ bending angle.

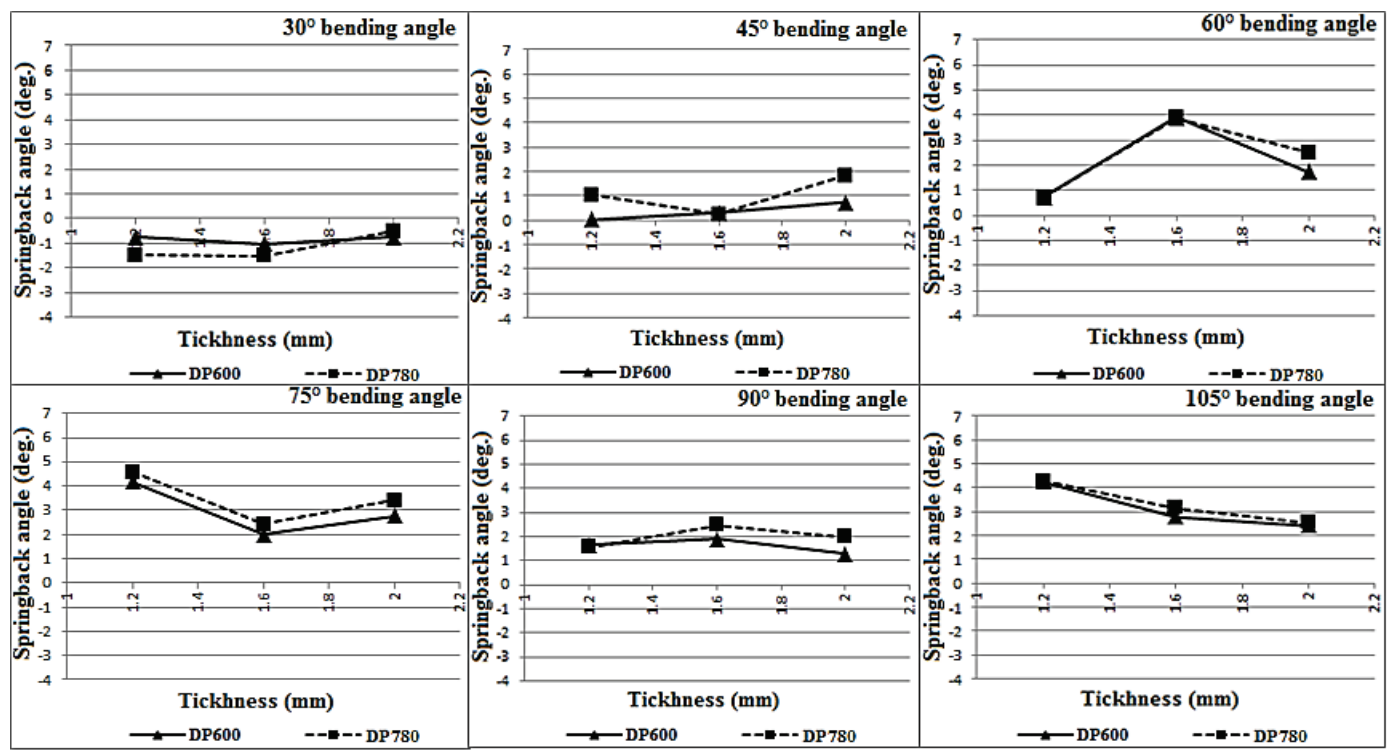

Figure 7 Variation of springback with material thickness at different bending angles for a punch tip radius of $3 \mathrm{~mm}$ (rolling direction: $45^{\circ}$ )

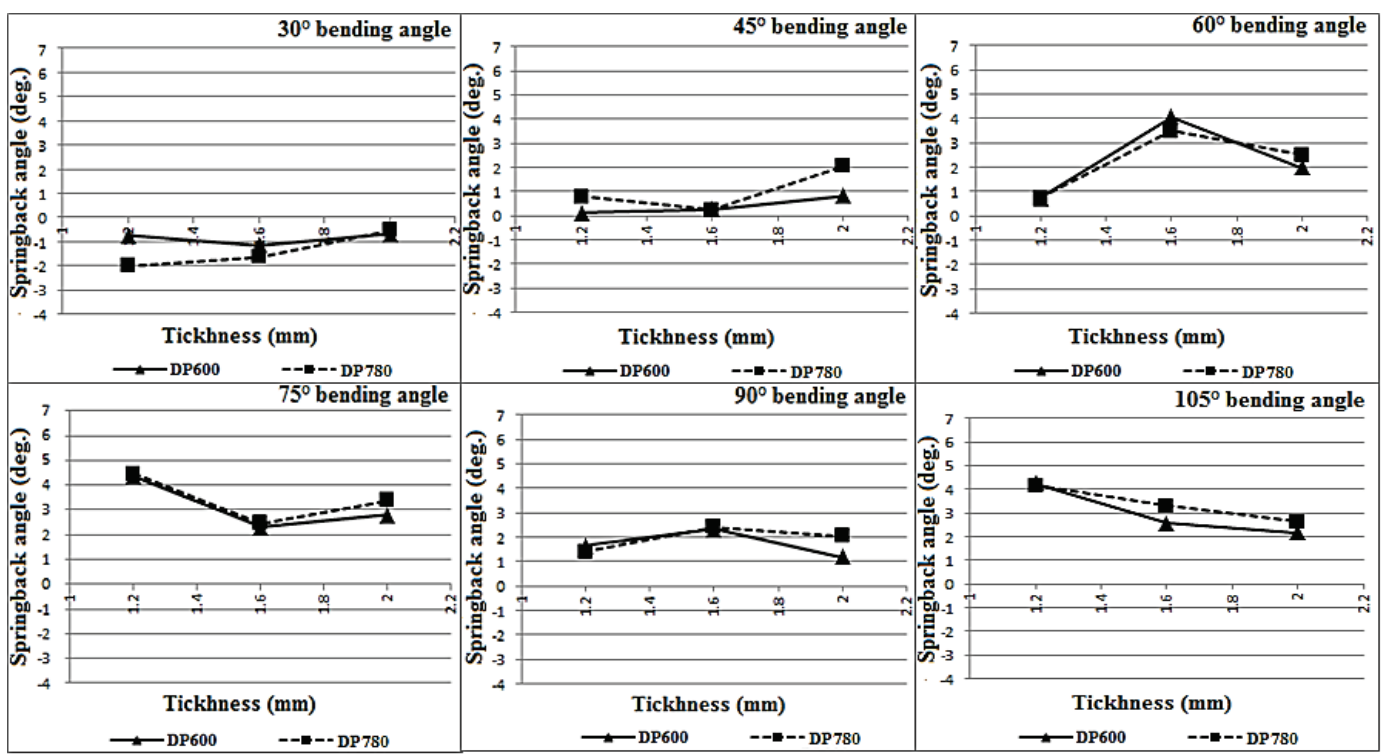

Figure 8 Variation of springback with material thickness at different bending angles for a punch tip radius of $3 \mathrm{~mm}$ (rolling direction: $90^{\circ}$ )

\subsection{Measurements with $4 \mathrm{~mm}$ Punch Radius}

The distributions of springback values in relation to material thickness is presented in Fig. 9 for a punch tip radius of $4 \mathrm{~mm}$ in the rolling direction of $0^{\circ}$ and for the bending angles of $30^{\circ}, 45^{\circ}, 60^{\circ}, 75^{\circ}, 90^{\circ}$ and $105^{\circ}$. For the $30^{\circ}$ bending angle, no springback/springforward was seen with any thicknesses in the DP780, but first increased then approached zero in the DP780. Unlike the previous measurements, the springforward appeared for the $45^{\circ}$ and $60^{\circ}$ bending angles, rather than the $30^{\circ}$, at all measured points, and fell to $3^{\circ}$ at a thickness of $1.6 \mathrm{~mm}$. The springback for the $90^{\circ}$ bending angle rose with increased material thickness. The springback was almost negligible for $75^{\circ}$ and remained almost constant around $1^{\circ}$ for the $105^{\circ}$ bending angle in the DP780. These findings proved that the effect of the punch radius on springforward was more influential than that of the rolling direction, which is partly in accord with Bakhshi-Jooybari et al. [8] and Davoodi and Zareh-Desari [14].

The springback for the punch tip radius of $4 \mathrm{~mm}$ and the bending angles of $30^{\circ}, 45^{\circ}, 60^{\circ}, 75^{\circ}, 90^{\circ}$ and $105^{\circ}$ in the rolling direction of $45^{\circ}$ is shown oin Fig. 10. The measured springback values in the diagonal direction were the same as in the zero rolling direction (no deviation in DP780) at the $30^{\circ}$ bending angle, but springforward ranging from $3^{\circ}$ to $1^{\circ}$ was observed, particularly at $45^{\circ}$, and it seemed to appear up to the $60^{\circ}$ bending angle. Similar results were also presented by Garcia-Romeu et al. [5], Bakhshi-Jooybari et al. [8], Barouzeh and Mondali [11] and Dilipak et al. [13]. The springback declined with the material thickness at the $75^{\circ}$ bending angle and crossed the 
zero line at $1.85 \mathrm{~mm}$ material thickness, corresponding to the critical value $(A)$ of 1.92 , resulting in springforward. The springback increased with the material thickness at $90^{\circ}$, but decreased only slightly for the DP600 for the $105^{\circ}$ bending angle.

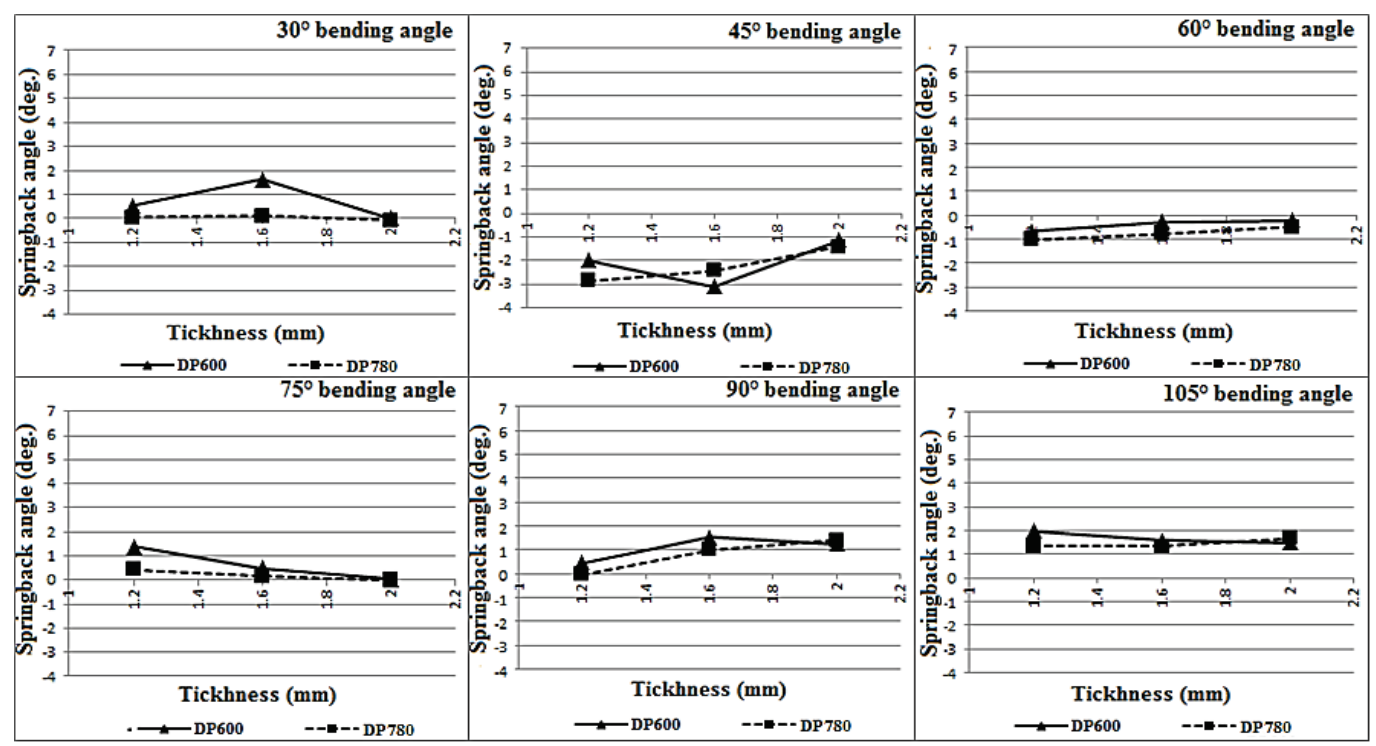

Figure 9 Variation of springback with material thickness at different bending angles for a punch tip radius of $4 \mathrm{~mm}$ (rolling direction: $0^{\circ}$ )

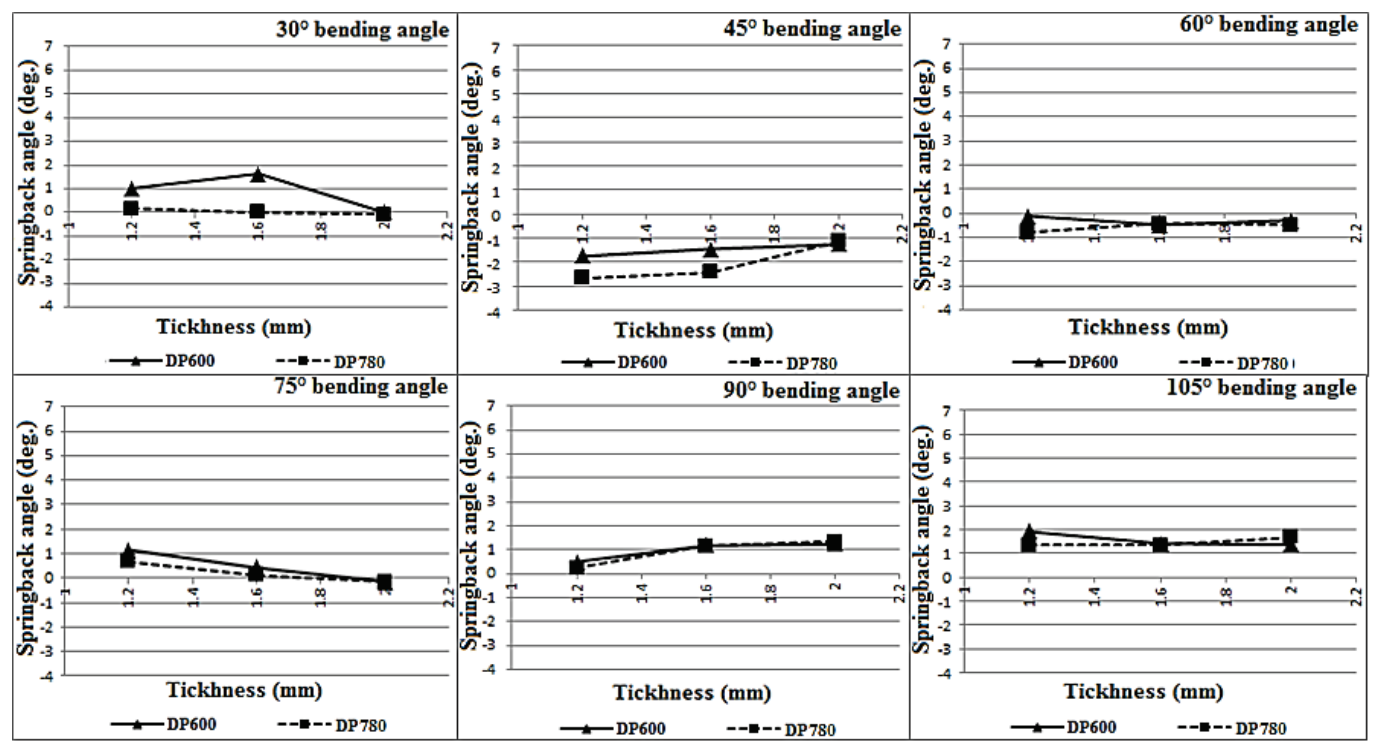

Figure 10 Variation of springback with material thickness at different bending angles for a punch tip radius of $4 \mathrm{~mm}$ (rolling direction: $45^{\circ}$ )

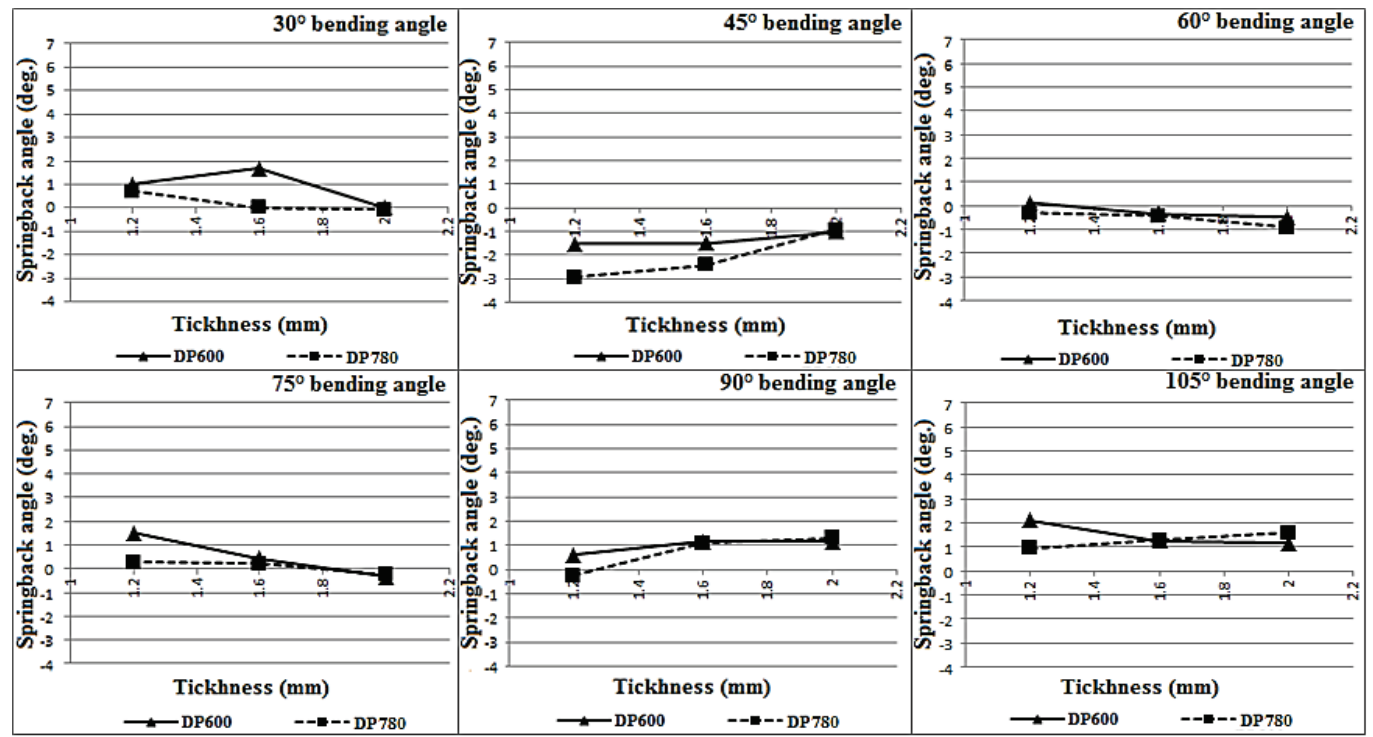

Figure 11 Variation of springback with material thickness at different bending angles for a punch tip radius of $4 \mathrm{~mm}$ (rolling direction: $90^{\circ}$ ) 
Fig. 11 shows the springback deviations for the punch tip radius of $4 \mathrm{~mm}$ in the rolling direction of $90^{\circ}$ for the bending angles of $30^{\circ}, 45^{\circ}, 60^{\circ}, 75^{\circ}, 90^{\circ}$ and $105^{\circ}$, respectively. The springback values for $30^{\circ}$ bending decreased and became zero at midpoint in the DP780, but first increased and then decreased in the DP600. On the other hand, springforward was observed as high as $3^{\circ}$ from the $45^{\circ}$ up to $90^{\circ}$ bending angles. Springback diminished with the material thickness at $60^{\circ}$ and $75^{\circ}$ bending and gave rise to springforward after the critical value of 1.92 . It can also be said that the springback increased with the material thickness both at $90^{\circ}$ and $105^{\circ}$, except in the DP600 for $105^{\circ}$.

These measurements showed that the springback values can be reduced by increasing the bending angle for the tip radii of $3 \mathrm{~mm}$ and $4 \mathrm{~mm}$, and that the enhancement of both the punch radius and the rolling direction (less influential) suppressed springback development and induced it to springforward, particularly at lesser bending angles. In contrast, the springback angle rose along with bending angles only for the punch radius of $2 \mathrm{~mm}$. As the punch radius and rolling direction increased, the springback decreased, i.e., the maximum springback was almost $6^{\circ}$ for the $2 \mathrm{~mm}$ punch radius in the parallel direction, but it remained below $4.5^{\circ}$ and $2^{\circ}$ for $3 \mathrm{~mm}$ and $4 \mathrm{~mm}$ punch radii in the perpendicular direction, respectively.

\section{CONCLUSION}

In this study, the springback/springforward performance of DP600 and DP780 steel with different sheet thicknesses, punch tip radii, rolling directions and $\mathrm{V}$ bending degrees was experimentally investigated, and the following remarks summarise the most substantial conclusions that can be drawn:

- The measurements showed that the springback/springforward values of the high-carbon concentrated DP780 consistently remained greater than those of the DP600.

- The springback decreased with material thickness and curvature radius. On the other hand, the springback increased with the bending angle only for the small tip radius of $2 \mathrm{~mm}$ and decreased for the larger tip radii of 3 and $4 \mathrm{~mm}$.

- The enhancement of the ratio of curvature radius to material thickness $\left(r t^{-1}\right)$ also caused the springback to decrease.

- A new dimensionless parameter was developed and the critical value of 1.92 was obtained in order to determine the transition point from springback to springforward.

- This study also found that springback can be reduced by increasing the bending angle for the larger tip radii of 3 and $4 \mathrm{~mm}$. Conversely, the springback angle increased with the bending angles, particularly for the tip radius of $2 \mathrm{~mm}$.

- The enhancement of both the punch radius and the rolling direction suppressed springback development and subsequently brought about the transition to springforward, especially for small bending angles.

- As the punch radius and rolling direction increased, the extent of springback decreased, i.e., the maximum springback was almost $6^{\circ}$ for the $2 \mathrm{~mm}$ punch radius in the parallel direction, but it remained below $4.5^{\circ}$ and $2^{\circ}$ for the $3 \mathrm{~mm}$ and $4 \mathrm{~mm}$ punch radii, respectively, in the perpendicular direction.

\section{Acknowledgements}

The financial support for this research project, OUAP (M-2013/10), provided by the Scientific Research Fund of Uludag University is gratefully acknowledged.

\section{REFERENCES}

[1] Carden, W. D., Geng, L. M., Matlock, D. K., \& Wagone, R. H. (2002). Measurement of springback. International Journal of Mechanical Sciences, 44, 79-101. https://doi.org/10.1016/S0020-7403(01)00082-0

[2] Moon, Y. H., Kang, S. S., Cho, J. R., \& Kim, T. G. (2003). Effect of tool temperature on the reduction of the springback of aluminium sheets. Journal of Materials Processing Technology, 8, 132-365. https://doi.org/10.1016/S0924-0136(02)00925-1

[3] Tekaslan, O., Şeker, U., \& Özdemir, A. (2006). Determining springback amount of steel sheet metal has $0.5 \mathrm{~mm}$ thickness in bending dies. Materials \& Design, 27, 251-258. https://doi.org/10.1016/j.matdes.2004.10.006

[4] Ragai, I., Lazim, D., \& Nemes, J. A. (2005). Anisotropy and springback in draw-bending of stainless steel 410: experimental and numerical study. Journal of Materials Processing Technology, 166, 116-127. https://doi.org/10.1016/j.jmatprotec.2004.08.007

[5] Garcia-Romeu, M. L., Ciurana, J., \& Ferrer, I. (2007). Springback determination of sheet metals in an air bending process based on an experimental work. Journal of Materials Processing Technology, 191, 174-177. https://doi.org/10.1016/j.jmatprotec.2007.03.019

[6] Tekaslan, O., Gerger, N., \& Seker, U. (2008). Determination of spring-back of stainless steel sheet metal in $\mathrm{V}$ bending dies.Materials \& Design, 29, 1043-1050. https://doi.org/10.1016/j.matdes.2007.04.004

[7] Rahmani, B., Alinejad, G., \& Bakhshi-Jooybari, M. (2009). An investigation on springback/negative springback phenomena using finite element method and experimental approach. Proceedings of the Institution of Mechanical Engineers Part B Journal of Engineering Manufacture, 223(7), 841-850. https://doi.org/10.1243/09544054JEM1321

[8] Bakhshi-Jooybari, M., Rahmani, B., Daeezadeh, V., \& Gorji, A. (2009). The study of spring-back of CK67 steel sheet in V-die and U-die bending processes. Materials \& Design, 30, 2410-2419. https://doi.org/10.1016/j.matdes.2008.10.018

[9] Narayanasamy, R. \& Padmanabhan, P. (2010). Influence of Lubrication on Springback in Air Bending Process of Interstitial Free Steel Sheet. Journal of Materials Engineering and Performance, 19, 246-251. https://doi.org/10.1007/s11665-009-9479-6

[10] Parsai, M. H., Nasher, Al Ahkami, S., \& Ettehad, M. (2010). Experimental and finite element study on the springback of double curved aluminum/polypropylene/aluminum sandwich sheet. Materials \& Design, 31, 4174-4183. https://doi.org/10.1016/j.matdes.2010.04.024

[11] Barouzeh, M. R. \& Mondali, M. (2011). Springback Investigational Warm V- bending Conditions by Numerical and Experimental methods. International Conference on Trends in Mechanical and Industrial Engineering ICTMIE, Bangkok.

[12] Chongthairungruang, B., Uthaisangsuk, V., Suranuntchai, S., \& Jirathearanat, S. (2012). Experimental and numerical 
investigation of springback effect for advanced high strength dual phase steel. Materials \& Design, 39, 318-328. https://doi.org/10.1016/j.matdes.2012.02.055

[13] Dilipak, H., Ozdemir, M., \& Sarıkaya, M. (2013). Effects of Material Properties and Punch Tip Radius on SpringForward in 90 degrees V Bending Processes. Journal of Iron and Steel Research International, 20(10), 64-69.

https://doi.org/10.1016/S1006-706X(13)60178-8

[14] Davoodi, B. \& Zareh-Desari, B. (2014). Assessment of forming parameters influencing spring-back in multi-point forming process: A comprehensive experimental and numerical study. Materials \& Design, 59, 103-114. https://doi.org/10.1016/j.matdes.2014.02.043

[15] Grizelj, B., Cumin, J., \& Grizelj, D. (2012). Effect of SpringBack and Spring-Forward in V-die Bending of St1403 Sheet Metal Plates. Strojarstvo, 52(2), 181-186.

[16] Tekiner, Z. An experimental study on the examination of springback of sheet metals with several thicknesses and properties in bending dies. Journal of Materials Processing Technology, 145, 109-117.

https://doi.org/10.1016/j.jmatprotec.2003.07.005

\section{Contact information:}

Yeliz UMUR, Lecturer, Ing., PhD

Uludag University, Engineering Faculty,

Mechanical Engineering Department,

16059, Gorukle-Bursa, Turkey

E-mail: ylz@uludag.edu.tr

Hakan AYDIN, Associate Professor, Ing., PhD

(Corresponding author)

Uludag University, Engineering Faculty,

Mechanical Engineering Department,

16059, Gorukle-Bursa, Turkey

E-mail: hakanay@uludag.edu.tr

Kurtulus YIGIT, Lecturer, Ing., PhD

Uludag University, Engineering Faculty,

Mechanical Engineering Department,

16059, Gorukle-Bursa, Turkey

E-mail: kyigit@uludag.edu.tr

Ali BAYRAM, Professor, Ing., PhD Uludag University, Engineering Faculty, Mechanical Engineering Department,

16059, Gorukle-Bursa, Turkey

E-mail: bayram@uludag.edu.tr 